\title{
Development of Fertilizer Apps (F Apps) for well informed Decision Making among the Farmers - Manikandam Block
}

\author{
Dr. M. Kalpana Ph.D ${ }^{1}$, Dr. D. Periyar Ramasamy Ph.D ${ }^{2}$, Dr. D. Jaya Kumar ${ }^{3}$ \\ Assistant Professor, Tamil Nadu Agricultural University, Coimbatore, India ${ }^{1}$ \\ Assistant Professor, Anbil Dharmalingam Agricultural College and Research Institute, Trichy, India2 \\ Professor, Horticulture College and \&Research Institute (Women), Trichy, India ${ }^{3}$
}

\begin{abstract}
India is an agricultural based country. In recent trends knowledge are upgraded by mobile enabled information services. Farmers need advice to take decision during their farming activities. Application of required amount of fertilizer at proper time and proper proportion will help in increasing the overall productivity of the farm and also safe guards the soil health and microbial biodiversity. This paper expresses the idea about the creation of Fertilizer Apps( F Apps) an android application that helps in delivering the rice crop specific fertilizer quantity to be applied. The idea is to calculate the amount of NPK fertilizers to be applied based on the blanket recommendation for the villages in Manikandam Block in Tiruchirappalli district. This application works based on the rice crop, village selected by the farmer and that is taken as input, thus providing the farmers with the blanket recommendation of the NPK fertilizers and the amount of Urea, SSP and MOP to be applied for selected village.
\end{abstract}

Keywords: NPK, Urea, SSP, MOP, Android App, NPK, Manikandam Block.

\section{INTRODUCTION}

Agriculture is the primary occupation of the larger part of Indian population. Today farmers are receiving diverse facts or information about faming like seeds, crop selection, crop processes, weather, fertilizer, pesticides etc. from various resources which are distributed on many different locations according to its origin, its processors, producers or vendors. The data having different format and may have different specific contents can be heterogeneous in their structure and format [1]. Therefore it is required to develop a system from where the required information is available to the farmer directly. The agriculture industry relies heavily on the use of NPK fertilizer. There are numerous building blocks of life that plants need for healthy growth. Soils often lack these elements, either naturally, or as a result of over cultivation, and needs to have these building blocks put back into it in the form of fertilizers.

NPK fertilizer is primarily composed of three main elements:

- Nitrogen $(\mathrm{N})$, Phosphorus (P), and Potassium (K), each of these being essential in plant nutrition. Among other benefits, Nitrogen helps plants grow quickly, while also increasing the production of seed and fruit, and bettering the quality of leaf and forage crops. Nitrogen is also a component of chlorophyll, the substance that gives plants their green color, and also aids in photosynthesis.

- Phosphorus, also a key player in the photosynthesis process, plays a vital role in a variety of the things needed by plants. Phosphorus supports the formation of oils, sugars, and starches. The transformation of solar energy into chemical energy is also aided by phosphorus, as well as in development of the plant, and the ability to withstand stress. Additionally, phosphorus encourages the growth of roots, and promotes blooming.

- Potassium, the third essential nutrient plants demand, assists in photosynthesis, fruit quality, the building of protein, and the reduction of disease.

The amount of nutrient available to the plant from the applied amount of fertilizers is usually left neglected and fertilizers are either over applied or not sufficiently applied. In Manikandam Block the major crop is rice. So F apps are developed to compute amount of nutrient from the fertilizers to be applied for rice crop. This helps the farmers to protect the loss incurred due to the over or under application of fertilizer.

Manikandam Block in Tiruchirappalli district has 20 villages. F Apps helps the farmers in Manikandam block to get the amount of Urea, SSP, MOP to be applied for rice crop. The recommendations are displayed for the 20 villages in Manikandam Block.

\section{REVIEW OF LITERATURE}

\section{Maha-Farm:}

Agro based crop information, Weather updates, Daily market prices and news/loan informational updates are 
included in the android application to help the farming community [2].

\section{Android Application for Agriculture Decision Support System:}

Android application helps the farmers to cultivate the suitable crops and to increase the productivity ratio. The application requires the basic inputs like water availability in $\mathrm{mm}$, average temperature, average soil $\mathrm{pH}$ of farm, locality of farm, soil type. Based on the input android application shows the probable crops for that farm [3].

\section{FarmManager}

The FarmManager are designed and developed to respond the needs and Characteristics of farmers of Greek. It can store database, do farm customization, easy field management, land field data, easy job recording process, employees and equipment [4].

\section{AgroMobile}

Developed especially for the Indian farmers to assist them in agricultural needs. It is used for botanical species recognition and disease detection using a simple mobile phone with camera [5].

\section{E-agree}

Used to detect detects leaf diseases. Provides online market place, market rate guide, weather report and soil information to the farmer [6].

\section{Agriculture Supply Chain Management}

Package developed for sugarcane farmers to obtain good production with proper management[7].

\section{Scheduling, Controlling and Monitoring of Agricultural Devices}

Used to farmer in controlling the motor and pesticides proportion, monitoring the farming activities going on in the farm remotely and also allow for improving the efficiency of the irrigation process [8].

\section{Solution for farmer consumer interaction}

Provide information to the farmers about how to get access to better inputs and gain more productivity; get connected to the end consumers. Provides information from the initial stage when the seed is germinated till the final stage when the crop is ready for harvest[9].

\section{DESIGN OF F APPS}

\section{A. Input}

F Apps application has an in-app database for rice crop in the manikandam block villages. These villages are listed in a combo box from which the user could select the specific village of interest. This selection is taken as input from the user, with the computation the output is displayed to the farmers.

The diagrammatic representation of F Apps is shown in fig 1.

\section{F Apps Algorithm}

Step 1: Get the input-Village of interest from the user. Step 2: Retrieve the blanket recommendation of the selected village from the in-app database.

Step 3: Display the blanket recommendation ratio of nitrogen, phosphorus and potassium for selected village in Manikandam Block.

Step 4: Calculate the amount of urea for nitrogenous fertilizer from the recommendation ratio using the formulae Nitrogen ratio*2.17.

Step 5: Calculate the amount of Single super phosphate for phosphorus fertilizer from the recommendation ratio using the formulae phosphorus ratio*6.25.

Step 6: Calculate the amount of Muriate of Potash for potassium fertilizer from the recommendation ratio using the formulae potassium*1.67.

Step 7: These calculations give the amount of fertilizer to be applied at the rate of kilograms/hectare.

Step 8: These results are then displayed on the application screen.

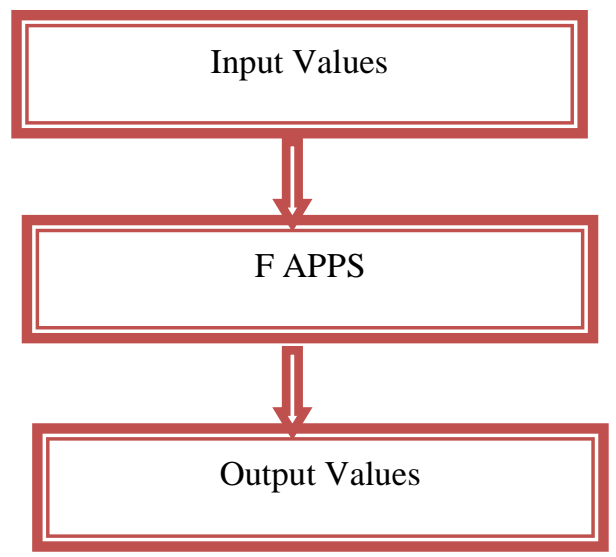

Fig. 1. Diagrammatic representation of AgroNutri App

\section{Output}

The output of the application is the amount of fertilizer to be applied to the specified village at the rate of kilograms/hectare. The output data is categorized in the form of displaying the amount of urea for nitrogen, single super phosphate for phosphorus and Muriate of Potash for potassium which is shown in Fig 2 and Fig 3.

\section{Experimental Results}

Android software development is the process by which new applications are created for the Android operating system. Applications are usually developed in the Java programming language using the Android Software Development Kit, but other development tools are available. The Android Software Development Kit (SDK) includes a comprehensive set of development tools. These include a debugger, libraries, a handset emulator based on QEMU, documentation, sample code, and tutorials.

F Apps was implemented using android operating system with KitKat as target version and Froyo 2.2 as minimum operating system requirement. 
Vol. 5, Issue 12, December 2016

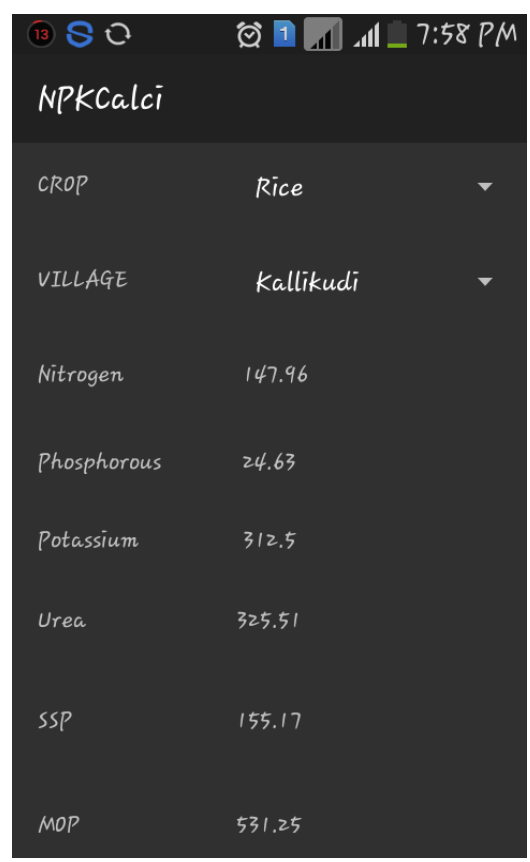

Fig. 2. Screen shot of user interaction

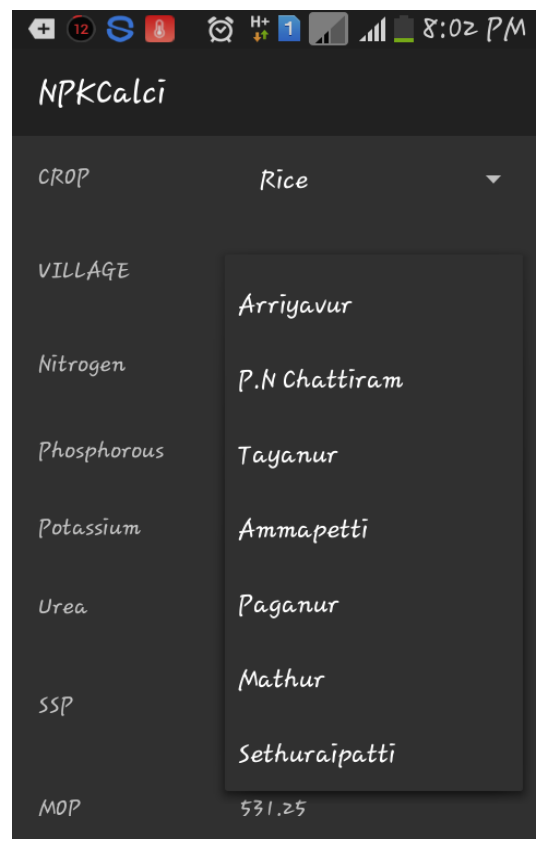

Fig. 3. Screen shot with list of villages in Manikandam Block

F Apps is an android application that provides farmers with the village specific nutrient requirement and amount of fertilizer to be applied for rice crop. F Apps features an inbuilt database with the villages in manikandam block for the blanket recommendation of rice crop.

The farmers start interacting with the F Apps by selecting the village name for which the blanket recommendation ratio of major nutrients like Nitrogen, Potassium and Phosphorus for the selected village is displayed. This ratio of Nitrogen, Phosphorus and Potassium are then taken for computing the amount of Urea, Single Super Phosphate and Muriate of Potash to be applied for the rice at the rate of kilogram per hectare. Once computed, these values are displayed from which farmers can get the information about the amount of fertilizer that has to be applied for their cultivated land.

The study would provide a better understanding about the quantum of fertilizer required for crop. The outcome will offer suitable option to solve over dosage of fertilizer application by the farmers. The findings will also help the extension worker to develop appropriate strategies to educate the farmers and inculcate required knowledge to improve the application of fertilizer dosage. This finding will help in formulating appropriate strategies by the policy makers and scientist to develop suitable mechanism to enhance the efficient fertilizer application.

\section{CONCLUSION}

F Apps is developed for the farmers in Manikandam Block in Tiruchirappalli district. F Apps helps the farmers in delivering the specific fertilizer quantity to be applied for rice crop to reduce the cost incurred for them in application of fertilizer. The productivity of the farm is increased by application of appropriate proportion of major nutrients. Future scope of F Apps is to incorporate the entire district in Tamil Nadu which would help the farming community to reduce the cost incurred in the application of fertilizer.

\section{REFERENCES}

[1] Steinberger, G., Rothmund, M., \& Auernhammer, H. (2009) Mobile farm equipment as a data source in an agricultural service architecture \| , Computers and Electronics in Agriculture, 65(2), 238-246.

[2] Aniket Bhave, Rahul Joshi, Ryan Fernandes(2014) - MahaFarm An Android Based Solution for Remunerative Agriculture \|, International Journal of Research in Advent Technology, Vol.2, No.4

[3] Rachana P. Koli1 , V. D. Jadhav2 (2015), - Agriculture Decision Support System As Android Application II , International Journal of Science and Research, Vol. 4 Issue 4

[4] Lantzos, T., Koykoyris, G., \& Salampasis, M. (2013) -FarmManager: an Android application for the management of small farms II , Procedia Technology, 8, 587-592.

[5] Prasad, S., Peddoju, S. K., \& Ghosh, D. (2013) - AgroMobile: A Cloud-Based Framework for Agriculturists on Mobile Platform \|, International Journal of Advanced Science and Technology, 59, 41-52.

[6] Santosh Reddy, Abhijeet Pawar, Sumit Rasane, Suraj Kadam (2015) - A Survey on Crop Disease Detection and Prevention using Android Application II, International Journal of Innovative Science, Engineering \& Technology, Vol. 2, Issue 4

[7] Monika Chirmade, Komal Tayade, Gaurav Sham Bankar, Shounak Sugave (2015) - Agriculture Supply Chain Management Based Android Application \|, International Journal of Advanced Research in Computer and Communication Engineering, Vol. 4, Issue 4

[8] Mukesh Choudhary, Sumeet Dhone, Akshay Jadhav, Chetan Dhandal, Prof. J. M. Nighot (2015) - Scheduling, Controlling \& Monitoring of Agricultural Devices Using Android Application II, International Journal of Advanced Research in Computer Engineering \& Technology,Vol.4,Issue 4

[9] Deshpande Radhika, Bhalekar Dipali, Mutkule Prasad, Sanjay Pandhare, Nawale Akshay(2015) - One Stop Solution for Farmer Consumer Interaction II , IJCA Proceedings on National Conference on Advances in Computing NCAC (6):16-19 